\title{
Isolamento social vivenciado por mulheres no pós-parto durante a pandemia da
}

\section{Covid-19}

\author{
Social isolation experienced by postpartum women during the Covid-19 pandemic \\ Aislamiento social experimentado por mujeres posparto durante la pandemia de Covid-19
}

Recebido: 28/09/2021 | Revisado: 05/10/2021 | Aceito: 15/10/2021 | Publicado: 17/10/2021

\author{
Greice Machado Pieszak \\ ORCID: https://orcid.org/0000-0003-4980-3253 \\ Universidade Federal de Santa Maria, Brasil \\ E-mail: greicepieszak@gmail.com \\ Giovana Calcagno Gomes \\ ORCID: https://orcid.org/0000-0002-2464-1537 \\ Universidade Federal do Rio Grande, Brasil \\ E-mail: giovanacalcagno@furg.br \\ Adriane Maria Netto De Oliveira \\ ORCID: https://orcid.org/0000-0001-9422-423X \\ Universidade Federal do Rio Grande, Brasil \\ E-mail: adrianemnoliveira@ furg.br \\ Pâmela Kath De Oliveira Nörnberg \\ ORCID: https://orcid.org/0000-0002-5931-3234 \\ Universidade Federal do Rio Grande, Brasil \\ pamelakathpko@yahoo.com.br \\ Cristina Saling Kruel \\ ORCID: https://orcid.org/0000-0003-1996-7708 \\ Universidade Franciscana, Brasil \\ E-mail: cristinaskruel@gmail.com \\ Andressa Rodrigues Peripolli \\ ORCID: https://orcid.org/0000-0002-7599-4674 \\ Instituto Federal Farroupilha, Brasil \\ E-mail: andressaufsm@hotmail.com
}

\begin{abstract}
Resumo
Objetivo: Conhecer os aspectos positivos e negativos do isolamento social vivenciado por mulheres no pós-parto durante a pandemia da Covid-19. Metodologia: Realizou-se uma pesquisa qualitativa que teve como referencial metodológico a Grounded Theory. Participaram 14 puérperas que tiveram seus partos em um hospital do sul do Brasil. Os dados foram coletados no segundo semestre de 2020 por entrevistas, sendo analisados pelas codificações aberta, axial e seletiva. Resultados: Como positivo referiram poder conduzir suas ações com seu bebê sem intromissões no seu maternar; menor preocupação com o contágio pela Covid-19. Relataram tranquilidade para estabelecer o aleitamento materno. Puderam atender as necessidades dos seus filhos de diferentes idades, tendo sua intimidade preservada. Reconheceram como negativo a necessidade do isolamento social e aderiram às medidas protetivas por medo do contágio. Manifestaram necessidades de convívio afetivo e desejo de dividir a alegria do nascimento do seu filho com outras pessoas. Vivenciaram o puerpério de forma solitária, insegura e exaustiva, sentiram falta de uma rede de apoio, sentindo-se sobrecarregadas frente às demandas do bebê, tarefas domésticas, tendo que administrar seus sentimentos. Considerações finais: $\mathrm{O}$ isolamento social acarretou forte impacto na vivência do puerpério, exigindo a mudança de planos e adaptações. O uso de formas alternativas de contato deve ser implementado como de mídias online como forma de mantê-las em contato social mesmo que distantes. O companheiro deve ser instrumentalizado para o cuidado tanto da puérpera como do recém-nascido, minimizando seu desgaste físico e mental.
\end{abstract}

Palavras-chave: Mulheres; Período pós-parto; Isolamento social; Covid-19; Enfermagem.

\begin{abstract}
Objective: To know the positive and negative aspects of social isolation experienced by postpartum women during the Covid-19 pandemic. Methodology: A qualitative research was carried using the Grounded Theory as methodological framework. 14 postpartum women who gave birth in a hospital in southern Brazil participated. Data were collected in the second half of 2020 through interviews, being analyzed using open, axial and selective coding. Results: As positive, they reported being able to conduct their actions with their baby no intrusion; less concern about contagion by Covid-19. They reported tranquility to establish breastfeeding. They were able to meet the needs of their children of different ages, their intimacy preserved. They recognized as negative the need for social isolation and adhered to protective measures for fear of contagion. They manifested needs for emotional interaction and desire to share the joy of their child's birth with other people. They experienced the puerperium was a solitary, insecure and
\end{abstract}


exhausting, felt the lack of a support network, feeling overloaded with the demands of the baby, household chores, having to manage their feelings. Final considerations: Social isolation had a strong impact on the puerperium experience, requiring changes in plans and adaptations. The use of alternative forms of contact should be implemented online media a way to keep them in social contact even if they are far away. The partner must be equipped to care for both the mother and the newborn, minimizing their physical and mental strain.

Keywords: Women; Postpartum period; Social isolation; Covid-19; Nursing.

\section{Resumen}

Objetivo: Conocer los aspectos positivos y negativos del aislamiento social que vivieron las mujeres em posparto durante la pandemia de Covid-19. Metodología: Se realizó una investigación cualitativa utilizando la Teoría Fundamentada como marco metodológico. Participaron 14 puérperas que dieron a luz en un hospital del sur de Brasil. Los datos fueron recolectados en el segundo semestre de 2020 a través de entrevistas, siendo analizados mediante codificación abierta, axial y selectiva. Resultados: Como positivo, informaron poder realizar sus acciones con su bebé sin intrusiones; menos preocupación por el contagio por Covid-19. Informaron tranquilidad para establecer la lactancia materna. Pudieron satisfacer las necesidades de sus hijos de diferentes edades, manteniendo su intimidad. Reconocieron como negativa la necesidad de aislamiento social y solamente adhirieron a las medidas de protección por temor al contagio. Manifestaron necesidades de interacción emocional y deseo de compartir la alegría del nacimiento de su hijo con otras personas. Vivieron el puerperio de forma solitaria, insegura y exhaustiva, sintieron la falta de una red de apoyo, sintiéndose sobrecargadas con las exigencias del bebé, las tareas domésticas, teniendo que manejar sus sentimientos. Consideraciones finales: El aislamiento social tuvo un fuerte impacto en la experiencia del puerperio, requiriendo cambios en los planes y adaptaciones. El uso de formas alternativas de contacto debe implementarse como medios en línea como una forma de mantenerlas en contacto social incluso si están distantes. Su compañero debe estar equipado para cuidar tanto a la madre como al recién nacido, minimizando su tensión física y mental.

Palabras clave: Mujeres; Período posparto; Aislamiento social; Covid-19; Enfermería.

\section{Introdução}

Estudos acerca do período gravídico-puerperal são considerados prioridades de Pesquisa em Saúde (Brasil, 2015), uma vez que, ainda são muito presentes as altas taxas de morbimortalidade materna e neonatal, consideradas no Brasil um problema de saúde pública (Brasil, 2018). Pesquisas científicas e tecnológicas em saúde são um componente indispensável à melhoria das ações de promoção, proteção e recuperação da saúde da população.

No final do ano de 2019, surgiu uma epidemia caracterizada pelo aumento de pacientes com infecção respiratória originário de um novo coronavírus $(\mathrm{CoV})$, já que os dados de sequenciamento genômico inicial deste vírus não correspondiam aos CoV sequenciados anteriormente. Esta nova cepa de CoV foi identificada pela sigla Covid-19 (2019-nCoV), denominado atualmente como síndrome respiratória aguda grave COV-2 (SARS-Cov-2). Seu surgimento ocorreu no Mercado Central, mercado de frutos do mar, na Cidade de Wuhan, província de Hubei, na China e se espalhou rapidamente por todo o país e, posteriormente, para outras regiões (Trilla, 2020; Who, 2020).

Essa epidemia se disseminou rapidamente tomando proporções mundiais. Devido à gravidade deste surto e o potencial de propagação em escala internacional, em 31 de janeiro de 2020 a Organização Mundial de Saúde (OMS) considerou esta doença como sendo uma Emergência de Saúde Pública de Interesse Internacional e, posteriormente, em 11 de março de 2020 passou a considerá-la como Pandemia (Trilla, 2020; Who, 2020).

Embora a maioria das pessoas com Covid-19 tenha doença leve, sem complicações, algumas terão doença grave. A probabilidade de desfechos negativos parece ser maior em idosos, doentes crônicos e imunossuprimidos. No entanto, pelas condições a serem consideradas para possíveis complicações da síndrome gripal, puérperas até duas semanas após o parto (incluindo aborto ou perda fetal) foram incluídas no grupo de risco (Brasil, 2020). Essas foram afetadas com medo de se contagiar e transmitir a doença para o filho, risco aumentado de contrair a doença ou apresentar complicações graves, tendo sua saúde abalada. Somou-se a isso o risco de morte e a incerteza quanto a eficácia dos tratamentos disponíveis e a segurança das vacinas (Mortazavi, Mehrabad, \& Kiaeetabar, 2021).

Puerpério ou período pós-parto é a fase em que ocorrem manifestações involutivas ao estado pré-gravídico, 
modificações locais e sistêmicas provocadas pela gravidez e parto. É dividido em três períodos: imediato (do $1^{\circ}$ ao $10^{\circ}$ dia após a parturição), tardio (do $10^{\circ}$ ao $45^{\circ}$ dia) e remoto (a partir do $45^{\circ}$ dia) (Rezende, 2015). Devido à pandemia as puérperas foram submetidas ao isolamento social. $\mathrm{O}$ isolamento social associado ao sentimento de insegurança e medo de contaminação podem intensificar problemas psicossociais maternos durante o puerpério. Durante a pandemia da Covid-19 as medidas sanitárias foram tomadas ao redor do mundo para tentar conter o coronavírus e evitar a contaminação (Chrzan-Dętkoś, Walczak-Kozłowska, \& Lipowska, 2021). Ficar em casa e sair apenas para atividades essenciais, manter distanciamento e isolamento social foram maneiras de restringir o contato entre pessoas para evitar a disseminação do vírus (Naurin et al., 2020).

Estudos apontaram que dúvidas e incertezas sobre os riscos à saúde provocados pela Covid-19 no período da pandemia foram fatores que elevaram o medo e a ansiedade entre as puérperas (Silva et al., 2021; Sahin, \& Kabakci, 2020). O isolamento social também levou os casais a enfrentarem problemas financeiros e laborais, sendo motivo de angústia (Nanjundaswamy et al., 2020). Tensões no relacionamento conjugal e sintomas de depressão e ansiedade foram associados a maior preocupação com as ameaças da Covid-19 à vida da mãe e do bebê após o parto (Lebel, MacKinnon, Bagshawe, Tomfohr-Madsen, \& Giesbrecht, 2020).

O medo da infecção por Covid-19 e a necessidade da manutenção do isolamento social impõe muitos desafios à vivência do puerpério. $O$ puerpério apresenta-se como um período de grande vulnerabilidade para a mulher, devido às adaptações hormonais e as alterações no contexto familiar e social que estão associados à chegada da criança. Nessa fase, o apoio familiar e profissional é imprescindível, porém durante o isolamento social, o suporte necessário à mulher pode não estar disponível devido ao afastamento dos membros da família e dos profissionais da saúde que constituiriam sua rede de apoio (Cardoso, Sousa, Rocha, Menezes, \& Santos, 2021; SBP, 2021).

Nesse contexto, a questão que norteou este estudo foi: que os aspectos positivos e negativos relacionados com o isolamento social influenciam a vivência do pós-parto durante a pandemia da Covid-19. Para respondê-la objetivou-se conhecer aspectos positivos e negativos do isolamento social vivenciados por mulheres no pós-parto durante a pandemia da Covid-19.

\section{Metodologia}

Realizou-se uma pesquisa com abordagem qualitativa do tipo descritiva e exploratória,. Utilizou-se como referencial metodológico a Grounded Theory (GT). A GT consiste na coleta, codificação e comparação simultânea e sistemática dos dados, permitindo aprofundar o conhecimento, dentro da multidimensionalidade da experiência cotidiana do ser humano, gerando uma teoria substantiva (Strauss \& Corbin, 2008). O estudo foi realizado no domicílio de puérperas que tiveram seus partos no hospital do município de Santiago no Rio Grande do Sul (RS). A seleção das participantes ocorreu de forma intencional, por meio do contato com o setor de epidemiologia da Secretaria Municipal de Saúde do município que disponibilizou as informações dos partos ocorridos no período da coleta de dados e também os contatos pessoais das puérperas (endereço e telefone). Em seguida, aplicaram-se os critérios de elegibilidade e, após identificadas as puérperas, realizou-se o primeiro contato por telefone, convidando-as a participar da pesquisa e apresentando-as os objetivos da mesma, bem como os preceitos éticos que seriam respeitados na condução do estudo.

Foram incluídas no estudo mulheres no puerpério, com 18 anos de idade ou mais, que tiveram seus partos na maternidade do município de Santiago (RS). Foram excluídas mulheres que após três tentativas de acesso via telefone e/ou no domicílio não foram encontradas, o que inviabilizou o contato e agendamento da entrevista. Também foram excluídas puérperas cujos recém-nascidos estivessem exigindo atendimentos especializados.

Destaca-se que todas as puérperas que aceitaram participar da pesquisa preferiram que o encontro fosse presencial em 
suas residências. No entanto, devido a situação pandêmica ${ }^{1}$, algumas puérperas verbalizaram o não desejo de participarem da pesquisa de forma presencial, por se sentirem inseguras em receberem visitas durante o isolamento social. Sendo assim, foi oferecida a possibilidade de participação virtual. Porém, mantiveram a recusa, justificando a dificuldade de acesso à internet ou pela própria sobrecarga e exclusividade nos cuidados ao bebê, gerando indisponibilidade. Suas decisões foram respeitadas e compreendidas.

Nesta conjuntura, a definição do número de participantes e também da criação dos grupos amostrais foi determinado pelo processo de amostragem teórica, como recomenda a $G T$, valorizando o significado dos depoimentos e a contemplação dos objetivos da pesquisa. Além disso, uma característica substancial da $G T$ é que a condução metodológica do processo de coleta de dados oportuniza a análise comparativa e constante desses dados, permitindo, assim, o apontamento dos eventos indicativos, da formação das categorias, e o pesquisador pode decidindo quais dados explorar e o desenvolvimento da teoria surge à medida que os dados são elucidados. A etapa de coleta de dados é efetuada até acontecer a saturação teórica, ou seja, até ocorrer a repetição ou a ausência de dados novos (Strauss, \& Corbin, 2008).

Portanto, identificaram-se as participantes do estudo e formaram-se os grupos amostrais. Estas, apresentaram variadas experiências sobre o objeto de estudo, que responderam da melhor forma à pergunta de pesquisa, fornecendo informações que oportunizaram o desenvolvimento de conceitos e a construção da teoria (Corbin, \& Strauss, 2015).

A identificação das participantes do estudo se deu ao desenvolver a transcrição, a leitura e releitura dos depoimentos, retomou-se as lembranças de cada cena vivida nas entrevistas, os comportamentos, as emoções, os olhares e os sentimentos. À medida que alguma palavra elucidada ganhava destaque, tornando-se marcante nos discursos das mulheres, essa era escolhida para identificar a participante do estudo, por valorizar um período singular em suas vidas, em que revelaram sentimentos e emoções ao revisitarem suas vivências.

Figura 1 - Nuvem de palavras caracterizando as participantes da pesquisa. Rio Grande/RS, Brasil, 2021.

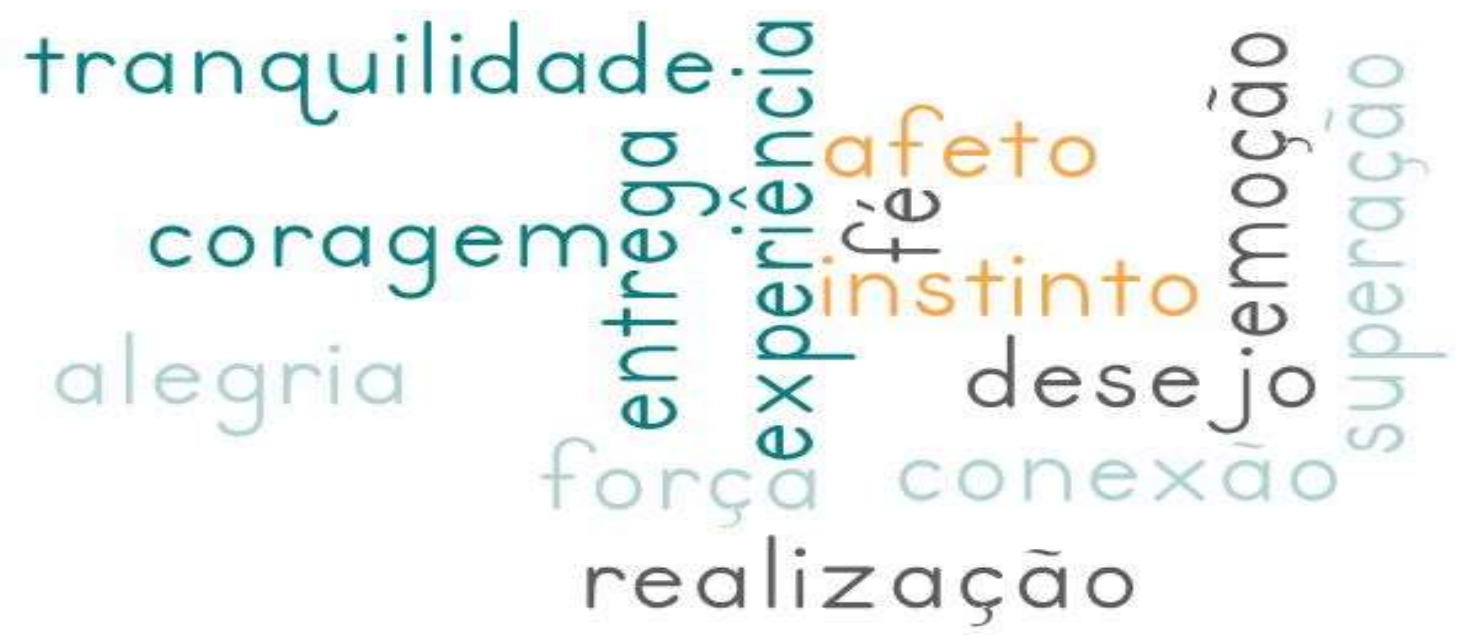

Fonte: Autores.

Formaram-se dois grupos amostrais. O primeiro foi composto por sete puérperas que estavam vivendo pela primeira vez a experiência de gestar, parir e maternar o seu bebê. O segundo foi formado por outras sete puérperas que estavam vivendo

\footnotetext{
${ }^{1}$ Em março de 2020, a OMS classificou como pandemia a doença conhecida como Covid-19, que é provocada pelo vírus SARS-CoV-2 e causa uma síndrome respiratória aguda grave, dentre outros acometimentos. Rapidamente esse agravo atingiu todo o mundo e a situação pandêmica foi considerada a maior ameaça mundial à saúde pública (Oms, 2020). Até a metade de junho de 2020 a OMS registrou mais de 8 milhões de casos e mais de 450.000 mortes em todo o mundo. Inclusive no Brasil, em agosto de 2020, período da coleta de dados desse estudo, confirmaram-se 3.164.785 casos da doença, nesse período, encontrava-se na segunda posição em número de casos no planeta (Brasil, 2020).
} 
essas experiências pela segunda ou terceira vez, na sua singularidade. A tabela a seguir apresenta os dois grupos amostrais:

Quadro 1 - Caracterização das participantes do estudo.

\begin{tabular}{|c|c|c|c|c|c|}
\hline $\begin{array}{c}\text { Grupos } \\
\text { amostrais }\end{array}$ & Identificação & Idades & $\begin{array}{c}\text { Número de } \\
\text { filhos }\end{array}$ & $\begin{array}{c}\text { Período } \\
\text { puerperal }\end{array}$ & Tipo de parto \\
\hline \multirow{7}{*}{ Grupo 1} & Afeto & 36 anos & \multirow{7}{*}{$\begin{array}{l}\text { Primeiro } \\
\text { filho(a) }\end{array}$} & 26 dias & Cesariana \\
\hline & Conexão & 28 anos & & 30 dias & Vaginal/natural \\
\hline & Realização & 26 anos & & 20 dias & Cesariana \\
\hline & Tranquilidade & 24 anos & & 15 dias & Cesariana \\
\hline & Emoção & 23 anos & & 27 dias & Cesariana \\
\hline & Fé & 27 anos & & 12 dias & Cesariana \\
\hline & Entrega & 24 anos & & 40 dias & Vaginal/natural \\
\hline & & & & & \\
\hline \multirow{7}{*}{ Grupo 2} & Desejo & 25 anos & 3 filhos & 17 dias & Cesariana \\
\hline & Superação & 26 anos & 2 filhos & 7 dias & Cesariana \\
\hline & Força & 33 anos & 2 filhos & 16 dias & Cesariana \\
\hline & Experiência & 29 anos & 2 filhos & 15 dias & Cesariana \\
\hline & Instinto & 32 anos & 2 filhos & 24 dias & Cesariana \\
\hline & Alegria & 28 anos & 2 filhos & 14 dias & Cesariana \\
\hline & Coragem & 29 anos & 2 filhos & 36 dias & Cesariana \\
\hline
\end{tabular}

Fonte: Autores.

O acesso ao domicílio se deu por meio da indicação do setor de epidemiologia da Secretaria Municipal de Saúde referente aos partos hospitalares ocorridos no período de coleta de dados. Em seguida, realizou-se o contato prévio por telefone, apresentando os objetivos da pesquisa e convidando às puérperas para participarem. No caso de aceite, agendou-se data e horário para a entrevista em seus domicílios.

A coleta de dados da pesquisa foi realizada por meio de entrevistas em profundidade, no período de julho a novembro de 2020. O projeto tramitou no Comitê de Ética em Pesquisa (CEP) da Universidade Federal do Rio Grande e foi aprovado no dia 10 de julho de 2020, sob o parecer número 4.148.001 e CAE: 0211720.0.0000.5324, dando início a coleta de dados. O instrumento de coleta de dados foi organizado em duas partes. A primeira composta por perguntas de caracterização dos participantes como: idade, ocupação, orientação religiosa, situação conjugal, escolaridade. E a segunda com as questões norteadoras que se remetem ao objetivo do estudo e possibilitavam às puérperas compartilharem sua experiência com a gestação, o parto, o nascimento do filho e o pós-parto. Essa condução está sustentada no referencial metodológico da GT, pois entrevistas em profundidade devem iniciar com um caráter mais concreto e gradualmente atingirem às experiências dos sujeitos (Silva, 2005).

Ressalta-se a preocupação com as medidas de proteção individual na condução das entrevistas com a utilização de máscara durante todo o período de permanência em seus domicílios, a higienização das mãos antes e depois das entrevistas, bem como a utilização de álcool em gel nas mãos e objetos usados e a retirada dos calçados e utilização de propés descartáveis para acessar suas residências. As entrevistas foram gravadas, conforme autorização das participantes, e transcritas na íntegra de forma literal. Sabe-se que o tempo destinado para a condução de cada entrevista é subjetivo e não foi limitado. A média de duração das entrevistas foram de cinquenta minutos. Destaca-se que entrevistas com duração de uma hora, levou oito horas intermitentes 
para serem transcritas, tal o grau de informações e significados compartilhados pela participante do estudo.

Ainda, quanto a realização da coleta e análise, seguiu-se às recomendações do referencial metodológico, realizando-as de forma simultânea. Portanto, após cada entrevista, foi realizada sua transcrição, no mais breve período de tempo possível. A transcrição apresentou-se como um momento muito importante porque, ao longo desta, era possível refletir acerca dos significados que as puérperas estavam tentando expressar.

A condução da transcrição também oportunizou a construção de notas teóricas que subsidiaram a análise. Utilizou-se a elaboração dos memos² ou memorandos que é considerada uma etapa essencial na GT, pois descrevem o histórico da interpretação do pesquisador e os resultados das codificações até a elaboração final da teoria. Estes, constituem-se como uma forma de registro referente à imagem visual das relações entre os conceitos e seus significados.

Foram elaboradas notas teóricas e notas de observação, conforme as sugestões de Schatzman, e Strauss (1973). As Notas de Observação (NO) são os registros dos eventos experienciados, vistos e ouvidos e as Notas Teóricas (NT) são as análises e inferências teóricas feitas durante a coleta e a interpretação dos dados. Nos memos, foram registradas as indagações que precisariam ser melhor explicitadas e com mais reflexão, sendo desenvolvidos durante a coleta e análise dos dados. São procedimentos registrados de análise de relatos, representando os insigths, na formação da teoria, empregados para guardar ideias sobre códigos, categorias e relações entre elas.

A análise dos dados de acordo com a GT trata-se de uma explicação conceitual e não interacional, pois não se realiza a descrição da "voz" das participantes e sim a elaboração de conceitos que dependem da coleta e análise dos dados, bem como a construção de memorandos sobre as categorias formadas. O processo central da análise dos dados é a codificação aberta, axial e seletiva (Glaser, \& Strauss, 1967). Na codificação aberta os dados foram codificados, comparados com outros dados e formadas as subcategorias e categorias iniciais. Na codificação axial, os dados foram agrupados de maneira nova, sendo feitas as conexões entre as categorias. Após foi realizada a codificação seletiva, estabelecendo uma relação entre as categorias, desenvolvendo a categoria central (Strauss, \& Corbin, 2008).

\section{Resultados}

A codificação dos dados gerou como categorias: Mantendo o isolamento social durante a pandemia, Reconhecendo os aspectos positivos do isolamento social no puerpério e Reconhecendo os aspectos negativos do isolamento social no puerpério.

\section{Mantendo o isolamento social durante a pandemia}

A manutenção do isolamento social foi uma estratégia preventiva utilizada pelas mulheres com o intuito protetivo. Na dimensão individual e relacional, elas são conscientes da gravidade da situação pandêmica, assumindo uma atitude de recolhimento e restrição de convivência. Optaram por não receber visitas, inclusive de pessoas do seu núcleo familiar. Algumas mulheres realizaram consultas médicas de forma online e utilizaram vídeo chamadas para apresentar o bebê aos familiares. A vivência de uma pandemia durante a gestação e o processo de parto e nascimento revelou a adesão a novas rotinas de autocuidado para proteger a si mesmas e seus bebês. Essa preocupação aflora na recém-mãe a capacidade de não subestimarem a importância do cuidado aderindo às restrições.

Nós estamos sem receber visitas por causa da pandemia. Nem os familiares mais próximos, eles não estão vindo aqui para conhecer o bebê. Estamos preocupados com isso tudo. Até essa nossa conduta gerou polêmica, mas a gente ficou

${ }^{2}$ Dá-se nome de memos às ideias emergentes dos dados que auxiliaram, posteriormente na análise destes, podem ser caracterizados como notas teóricas, metodológicas, reflexivas, de observação e outras. Possibilitam preservar as hipóteses, intuições e abstrações que emergem no processo de codificação. 
preocupado com a saúde do nosso bebê. Imagina ele nem tem as vacinas ainda. Até no dia do parto só avisamos a minha sogra. Ela era a única que ficou sabendo, porque a entrada no hospital era restrita em função da pandemia. A gente não quis causar tumulto e não expor ninguém. (Fé)

Com essa pandemia não estamos recebendo mais nenhuma visita. Até a gente precisou se organizar. Deixamos a minha filha mais velha na casa dos avós dela, na casa da minha sogra em isolamento para eu conseguir cuidar da bebê. Porque é uma situação que a gente não dá conta de tudo e não estamos contando com a nossa funcionária. Então, acumula tudo por fazer e mais a bebê recém-nascida e eu pós-cesariana. Não tem sido fácil. (Instinto)

Com toda essa pandemia as pessoas não se tocam e continuam visitando a gente. Estes dias eu criei coragem e pedi para as visitas não pegarem mais ela no colo. Disse que achava complicado receber visitas. As pessoas precisam se conscientizar que o bebê é frágil e todos precisamos nos cuidar. (Realização)

Acabamos de estar no hospital para o parto e vimos que a situação é séria. A gente passou medo de se contaminar com esse vírus. Aqui em casa a gente criou umas rotinas para a gente se cuidar mais: tirar os calçados para entrar em casa, manter a casa ventilada, usar sempre o álcool em gel e lavar bem às mãos, porque imagina, temos uma bebezinha recém-nascida em casa que ainda é bem frágil. (Alegria)

É uma situação delicada, durante toda a gestação estamos em isolamento social, convivendo apenas com os meus pais. [...] Inclusive as consultas médicas foram por ligações no auge da pandemia. E optamos por seguir assim, nos cuidando até nos sentirmos seguros para sair e conviver. (Afeto)

Até o momento ninguém veio ver o nosso bebê. Decidimos usar a opção de vídeo chamada para os nossos familiares conhecerem ele. (Emoção)

\section{Reconhecendo os aspectos positivos do isolamento social no puerpério}

As puérperas participantes do estudo acharam positivo poder conduzir suas ações com seu bebê, do seu modo, sem palpites ou intromissões no seu maternar. Referiram que por estarem isoladas, mantendo isolamento social, apresentaram uma menor preocupação de ter que dar satisfação às pessoas além de não precisar se preocupar com a questão do contágio, por terem restringido o contato. Relataram a tranquilidade de poder usufruir desse momento em família, sem o convívio com as demais pessoas. Acharam vantajosa a criação de uma rotina mais tranquila, pois conseguiram estabelecer o aleitamento materno em livre demanda e atender às necessidades dos seus filhos de diferentes idades.

Revelaram que, por estarem isoladas, conseguiram realizar seu autocuidado, valorizando o período do puerpério como íntimo. Reconheceram que não receber visitas nesse momento possibilita se conectarem mais com a criança, atendendo suas necessidades e preservando sua intimidade.

Com o isolamento a gente até que nem teve muitos palpites das pessoas, porque quase nem recebemos visitas. Então, ninguém se intrometeu no nosso jeito de cuidar dela. (Tranquilidade)

Mesmo morando com mais pessoas aqui em casa, decidimos não receber tantas pessoas e ficamos mais restritos, só nós mesmos, eu e meu marido e o nosso filho. A gente vai fazendo as coisas do nosso jeito e tem sido bem bom assim. 
(Emoção)

Para nós foi bem importante ficarmos só nós com nossos filhos, até para eu conseguir amamentar, dormir e descansar e aos poucos tudo foi fluindo bem. (Alegria)

Em cidade pequena tem disso, da gente receber aquela enxurrada de visitas logo que o bebê nasce. Com a pandemia não tivemos visitas inoportunas. (Conexão)

Sem ter que receber tanta visita a gente consegue se organizar melhor e descansar. (Superação)

Receber visitas também dá envolvimento para a gente. Eu sei porque com a minha primeira filha veio um monte de gente. (Experiência)

Sem receber tantas visitas eu fui conseguindo criar uma rotina mais tranquila com o nosso bebê, amamentar ele em livre demanda e também pude dar atenção aos meus dois filhos. (Força)

\section{Reconhecendo os aspectos negativos do isolamento social no puerpério}

A vivência do isolamento social no puerpério, fez com as puérperas vivenciassem uma experiência inesperada, que exigiu mudanças de planos e adaptações. Ao mesmo tempo em que às mulheres reconheciam a necessidade do isolamento social referiram ter aderido às medidas protetivas por medo do contágio. Elas também manifestaram necessidades do convívio afetivo, por considerar esse momento especial, pelo desejo de dividir a alegria do nascimento do seu filho com outras pessoas, mesmo as mais íntimas. Sentiram falta da presença física de outras mulheres de sua família, ou de amigas que já são mães. Relataram a ausência da emoção de visualizar seus pais, avós e irmãos segurarem seus filhos.

Ainda, as repercussões da restrição social no período puerperal, perpassou por uma vivência solitária, insegura e exaustiva. A ausência de uma rede de apoio física durante a pandemia acarretou em sobrecarga da mulher em tentar atender às demandas do bebê, as tarefas domésticas e a administração de seus sentimentos. As puérperas sentiram falta do contato físico, de ter com quem deixar o filho por alguns instantes, de receber um abraço, poder conversar e desejo de não se sentir sozinha nesse momento. Apresentaram medo do contágio mesmo estando em suas casas, tendo em vista o recebimento de visitas inesperadas.

A puérpera não imaginava ter que enfrentar dificuldades na condução com seus filhos, tendo que atender às necessidades de filhos com idades diferentes. Como a rede de apoio social foi comprometida a mulher se encontra sozinha e isolada, tentando dar conta das necessidades de cuidados tanto do filho recém-nascido quando dos outros. Testemunha as expectativas dos seus familiares e as decepções de não poderem acompanhar esse momento. Ela também se sente alijada da convivência com outras mulheres e sobrecarregada com os cuidados ao filho. Vivencias positivas com o parto e nascimento vão sendo apagadas no período puerperal e sendo substituídas pelas vivências negativas.

Sinto muita falta de poder conviver com mais pessoas, pois éramos acostumados a nos reunir com os amigos e agora estamos assim, isolados de todos. Eu achei que essa quarentena não ia se estender tanto porque a gente vai cansando de ficar sozinha. A gente tem vontade de mostrar nosso bebê para as pessoas, de interagir mais, mas não dá. Agora temos que esperar essa pandemia passar. Eu estou bem entediada com essa quarentena prolongada, porque a gente era acostumado a se reunir com as pessoas. É complicado querer se reunir e não poder, mas é necessário. Só que essa 
pandemia isolou a gente em um momento tão especial. (Alegria)

O lado complicado disso tudo, é não ter o contato físico com as pessoas que a gente gostaria de ter, com às mulheres da minha família, com as minhas amigas que já são mães e as pessoas mais próximas da gente. Saber que algumas pessoas importantes não vão conhecer meu bebê nos primeiros meses é bem triste. (Afeto)

Não poder dividir a alegria de ver teu filho no colo dos teus pais, dos teus avós, do teu irmão é difícil. (Fé)

Sinto falta de ter a quem recorrer em várias situações, poder deixar minha filha com alguém por um tempinho que fosse ou de um abraço, uma conversa. (Tranquilidade)

Acontecendo tudo isso com essa pandemia e não dando para fazer nada nossa ideia era poder sair passear com a nossa filha mais velha, que é uma coisa que ela gosta muito, mas não dá. A gente queria poder ter alguns momentos com ela para ela não sentir insegura, com ciúmes ou medos, mas não deu. Ela nos apresentou muitas necessidades no mesmo período que tínhamos uma bebê recém-nascida em casa. Chegou um ponto da pandemia que precisamos isolar nossa filha mais velha junto dos pais do meu esposo, assim eles ficariam protegidos e nos ajudariam a dar atenção para ela, pois não estávamos dando conta. [...]. (Instinto)

Com a pandemia, a gente se sobrecarregou bem mais. Minha filha mais velha que ia para a escola, tinha as amiguinhas dela, agora só em casa entediada, exigindo atenção da gente o tempo todo e a bebê também precisa de cuidados. Estou muito cansada. (Experiência)

Eu tive uma choradeira na primeira semana após o parto, sentia uma angustia muito grande, um aperto no peito, vontade de chorar, mas fui segurando esse choro e tentando enfrentar. Mas acho que com essa pandemia tudo foi se agravando quando comecei a receber as visitas inesperadas. Comecei a ficar com medo da minha filha pegar esse vírus, porque as pessoas chegam sem avisar, pedem para pegar no colo. Já senti muito medo de pegar o vírus no hospital e agora que estamos em casa fico com medo aqui. Eu sinto uma sensação muito ruim, porque pegam ela e não largam, não se tocam da gravidade do vírus e visitam a gente igual. Eu me sinto culpada por não ter coragem de falar que não quero que peguem ela, que não quero tantas visitas numa hora dessas. (Realização)

Com essa pandemia a sensação de solidão e insegurança se agravou. [...] Agora no pós-parto, eu não imaginava que os primeiros dias seriam tão desafiadores, cuidar do bebê, das tarefas domésticas, não ter muito com quem contar durante o isolamento é difícil. E a questão de não poder se relacionar com as pessoas, mesmo as próximas de ti, de poder sair um pouquinho, não ter alguns momentos só para mim. Esse período da licença maternidade tem sido bem solitário”. (Afeto)

\section{Discussão}

Para Mead (1970), a compreensão da experiência interior dentro dos processos vividos é fundamental para que o indivíduo selecione estímulos e construa respostas. A forma como cada puérpera vivenciou a necessidade do isolamento social neste período, administrando o cotidiano cheio de limitações, tem a ver com as condições presentes nos seus ambientes de 
(con)vivência e dos estímulos presentes nesses ambientes, permitindo-lhes interpretá-los como positivos ou negativos.

Verificou-se a presença de condições intervenientes relacionadas ao puerpério. Em relação ao isolamento social as puérperas participantes deste estudo reconheceram como aspectos positivos poder conduzir suas ações com seu bebê do seu modo, sem palpites ou intromissões no seu maternar, menos preocupação em dar satisfação às pessoas e não precisar se preocupar com a questão do contágio pela Covid-19 por terem restringido o contato. Relataram a tranquilidade de poder usufruir desse momento em família, conseguindo estabelecer uma rotina mais tranquila, estabelecerem o aleitamento materno em livre demanda e puderam atender as necessidades dos seus filhos de diferentes idades. Referiram poder se conectar mais com a criança, atender suas necessidades e ter sua intimidade preservada.

A Covid-19 surgiu no fim de 2019 na China e se mostrou altamente transmissível. Com o intuito de evitar que o vírus se espalhasse rapidamente, foram criadas medidas de prevenção, entre elas o isolamento social. Redobraram-se os cuidados com indivíduos enquadrados nos chamados grupos de risco, como as puérperas. Segundo a Secretaria de Atenção Primária à Saúde (SAPS), as puérperas apresentam maior risco de gravidade se infectadas pelo vírus (Brasil, 2019). Nesse sentido, o isolamento social tem por objetivo a redução do surgimento de novos casos a partir da diminuição da transmissão interpessoal pela tosse, espirro e toque, apresentando-se para essas puérperas como uma realidade a ser vivida.

As mães elencaram como positivo poderem estar em casa cuidando da saúde de sua família. Emergem, a partir do campo de sentido afetivo e emocional, sentimentos de satisfação e realização altamente significativos, que se vinculam ao fato dessas mulheres dispensarem cuidados importantes e necessários aos filhos e aos familiares. Ou seja, encontramos nesse campo sinais de que estamos diante de vidas dotadas de um sentido ético-emocional, na medida em que incluem uma forma de transcendência que as fazem perceber como positivo estar com seus bebês, atendendo suas necessidades e demandas (AielloVaisberg, Gallo-Belluzzo, \& Visintin, 2021).

As puérperas reconheceram como aspectos negativos do isolamento social a exigência de mudanças de planos e adaptações. Ao mesmo tempo em que reconheceram a necessidade do isolamento social referiram ter aderido às medidas protetivas por medo do contágio, manifestaram necessidades de convívio afetivo, considerando esse momento especial, com desejo de dividir a alegria do nascimento do seu filho com outras pessoas, pelo menos as mais íntimas. Sentiram falta da presença física de outras mulheres de sua família ou de amigas que já são mães e relataram a ausência da emoção de visualizar seus pais, avós e irmãos segurarem seus filhos.

Vivenciaram o puerpério de forma solitária, insegura e exaustiva. Sentiram falta da presença de uma rede de apoio, sentindo-se sobrecarregadas em tentar atender as demandas do bebê, realizar as tarefas domésticas e administrar seus sentimentos. Essa recém mãe sentiu falta do contato físico, de ter com quem deixar o filho, de receber um abraço, poder conversar, desejando não se sentir sozinha nesse momento. Ao mesmo tempo, referiram medo do contágio frente às visitas inesperadas. Além disso, enfrentaram dificuldades na condução com seus filhos com idades diferentes. Testemunharam as expectativas dos seus familiares, sentindo-se decepcionadas e magoadas por eles não acompanharem esse momento, alijadas dessa convivência.

As puérperas foram incluídas no grupo de risco do novo Coronavírus pelo Ministério da Saúde pela possibilidade de apresentarem casos mais graves da Covid-19, caso infectadas. A necessidade de isolamento social em decorrência da pandemia modificou planos e trouxe-lhes inseguranças e incertezas. O puerpério, já naturalmente marcado por mudanças físicas e hormonais importantes, tem um impacto significativo na vida da mulher lactante durante a pandemia, com mudanças nos hábitos de vida, podendo desencadear transtornos psicossociais, tais como ansiedade e depressão (Ferreira, Irigoyen, ConsolimColombo, Saraiva, \& Angelis., 2020, Mazzo, Brito, Silva, Feitosa, Lima, \& Silva, 2018).

Verifica-se a capacidade de adaptação da puérpera à maternidade e suas adversidades (Silva, Cardoso, Abreu, \& Silva 2020 a). No entanto, o isolamento social imposto pela pandemia tem submetido as puérperas ao enfrentamento de dificuldades 
de origens diversas, influenciando sua vivência da maternidade. Citam-se horas reduzidas de sono, choro constante do recémnascido, afazeres domésticos, cuidados com outros filhos, causando desgaste e cansaço para as mães. Estes aspectos negativos podem repercutir direta ou indiretamente na saúde materno-infantil, uma vez que durante o puerpério existe uma indissociabilidade entre mãe e bebê (Andrade, Santos, Maia, \& Mello 2015; Silva, Fonseca, Oliveira, Silva, Ramos, \& Gama, 2020 b).

Destaca-se um estudo fenomenológico de Lima, Santos, Erdmann, \& Souza (2018) que desvelou as experiências das mulheres que tiveram complicações puerperais e reações emocionais desencadeadas pela hospitalização. A vivência é marcada por sentimento de tristeza, desespero, frustração, negação e saudade, além dos medos da dor e da morte. Destacou-se inclusive o sofrimento percebido nas falas do ser-mulher-mãe e no choro expressado por elas durante as entrevistas.

Após o parto e nascimento, as mulheres revelaram sensação de cansaço que se acentuava no final de um longo dia, o qual a puérpera se envolveu com múltiplas tarefas, incluindo as tentativas de suprir as necessidades do recém-nascido e dos outros filhos com diferentes idades. Diante desse achado, destaca-se uma lacuna nas produções nacionais relacionada às experiências maternas no período puerperal, especialmente, neste tempo de emergência sanitária decorrente da pandemia da Covid-19.

Porém, um estudo qualitativo canadense de Rice, \& Williams (2021) avaliou, por meio de uma abordagem construtivista social, como as puérperas que deram à luz durante a pandemia foram afetadas. Constatou-se que as mulheres apresentavam sua saúde mental prejudicada, sendo influenciadas pela experiência negativa durante a permanência no hospital para o parto. A restrição da presença de pessoas de apoio tanto na hospitalização quanto em casa resultou em sofrimento e influenciou no desmame precoce. Além disso, as mulheres experimentaram o apoio online para a amamentação, mas este foi considerado ineficaz.

Ademais, o cansaço atribuído pelas puérperas deste estudo se dá também pela privação de sono. Consideram as noites mais complicadas, pois o bebê acorda várias vezes e, devido a isso, assumem uma condição de vigília, preocupadas em estarem atentas a qualquer manifestação dos seus filhos, suprindo suas necessidades. Suas noites não são mais de descanso e o sono não é reparador. Acentua-se o cansaço, quando a mulher desempenha os cuidados do bebê sozinha ou quando tem que atender ao outro filho. Também ficam cansadas no estabelecimento da amamentação exclusiva.

Destaca-se outra estratégia de ação realizadas pelas mulheres em relação ao desenvolvimento de habilidades com a maternidade, que envolvem desde as questões de autocuidado, de identificação das suas necessidades emocionais e de construção da própria rede de apoio para auxilio no processo de parto e nascimento. Essas ações também perpassam pelo reconhecimento de se manter em isolamento durante a pandemia para a proteção de si, de seu bebê e da sua família.

Identificou-se o reconhecimento de se manter em isolamento durante a pandemia para a proteção de si, de seu bebê e da sua família. Verifica-se, nesse sentido, a necessidade da implementação de medidas que ampliem e qualifiquem a rede de apoio social disponível às mulheres, incluindo a família e o companheiro, favorecendo o cuidado à mulher e ao recém-nascido. Tais ações devem auxiliar no vivenciar do seu maternar, com suporte suficiente para atender suas necessidades físicas e emocionais. Os profissionais atuantes na atenção básica, na rede privada e hospitalar precisam conhecer a realidade destas mulheres, intensificando suas estratégias de forma integral.

\section{Considerações Finais}

Até que a pandemia da Covid-19 passe, as gestações, partos e puerpérios serão vivenciados sob a égide do isolamento social, que minimiza a (con)vivência com as redes de apoio e submete as puérperas a protocolos que visam diminuir os riscos de contágio, sendo essas mulheres de risco aumentado caso se infectem. Neste sentido, devem ser ensinadas a se protegerem e se prevenir da infecção. O uso de formas alternativas de contato deve ser implementado como o uso das redes sociais e mídias 
online como e-mail e WhatsApp como forma de mantê-las em contato social mesmo que distantes. O companheiro deve ser instrumentalizado para o cuidado tanto da puérpera como do recém-nascido, minimizando seu desgaste físico e mental.

Uma limitação do estudo foi a imposição do distanciamento social devido a pandemia no período de coleta de dados, tendo várias recusas de puérperas na participação da pesquisa. Além disso, essa situação pandêmica impôs enormes restrições de acesso aos domicílios das puérperas. A utilização de recursos virtuais e de mídia na produção do conhecimento científico oportunizaria a obtenção de maior número de participantes e novas fontes de dados para pesquisa. É importante a realização de novos estudos visando avaliar as repercussões da Covid-19 para a saúde e o viver das puérperas, apontando estratégias de cuidado efetivas tanto da mulher quanto do recém-nascido.

\section{Referências}

Aiello-Vaisberg, T. M. J., Gallo-Belluzzo, S. R., \& Visintin, C. D. N. (2021). Maternidade e sofrimento social em tempos de Covid 19: estudo de Mommy Blogs. Pré-impressão / Versão 1. https://doi.org/10.1590/SciELOPreprints.356.

Andrade, R. D., Santos, J. S., Maia, M. A. C., \& Mello, D. F. (2015). Fatores relacionados à saúde da mulher no puerpério e repercussões na saúde da criança. Esc Anna Nery Rev Enferm, 19(1),181-186. 2015. https://www.scielo.br/j/ean/a/TJB8nBkghyFybLgFLK7XMpv/?lang=pt\&format=pdf

Brasil. (2019). Ministério da Saúde. Secretaria de Atenção Primária à Saúde. Departamento de Promoção da Saúde. Manual de Recomendações para a Assistência à Gestante e Puérpera frente à Pandemia de Covid-19. Ministério da Saúde, Secretaria de Atenção Primária à Saúde, Departamento de Promoção da Saúde. Brasília: Ministério da Saúde. 61 p. http://189.28.128.100/dab/docs/portaldab/documentos/corona/manual_recomendacoes_gestantes_covid19.pdf

Brasil. (2020 a). Ministério da Saúde. Secretaria de Atenção Especializada à Saúde. Departamento de Atenção Hospitalar, Domiciliar e de Urgência. Protocolo de manejo clínico da Covid-19na Atenção Especializada. 1 ed. rev. Brasília, DF. https://portalarquivos.saude.gov.br/images/pdf/2020/April/14/Protocolo-deManejo-Cl--nico-para-o-Covid-19.pdf

Brasil. (2020 b). Ministério da Saúde. Secretaria de Vigilância em Saúde. Boletim Epidemiológico 11. Doença pelo Coronavírus 2019 (COE - COVID-19). Brasília, DF: Ministério da Saúdehttps://portalarquivos.saude.gov.br/images/pdf/2020/April/18/2020-04-17---BE11---Boletim-do-COE-21h.pdf.

Cardoso, P. C., Sousa, T. M. de., Rocha, D. da S., Menezes, L. R. D. de., \& Santos, L. C. dos. (2021). A saúde materno-infantil no contexto da pandemia de COVID-19: evidências, recomendações e desafios. Rev. Bras. Saúde Matern. Infant., $21 \quad$ (Supl. 1), 221-228. https://www.scielo.br/j/rbsmi/a/3MYSwYYhwKnnFbNGQvWCcwH/?format=pdf\&lang=pt.

Chrzan-Dętkoś, M., Walczak-Kozłowska, T., \& Lipowska, M. (2021). The need for additional mental health support for women in the postpartum period in the times of epidemic crisis. BMC Pregnancy and Childbirth, 21(1), 1-9. https://doi.org/10.1186/s12884-021-03544-8.

Corbin, J., \& Strauss, A. (2015). Basics of qualitative researh: techniques and precedures for developing Grounded Theory. SAGE.

Ferreira, M. J., Irigoyen, M. C., Consolim-Colombo, F., Saraiva, J. F. K., \& Angelis, K. (2020). Vida Fisicamente Ativa como Medida de Enfrentamento ao COVID-19. Arq Bras Cardiol. AHEAD, 114(4), 601-602. http://publicacoes.cardiol.br/portal/abc/portugues/aop/2020/AOP_2020-0235.pdf.

Glaser, B. G. \& Strauss, A. (1967). The discovery of grounded theory: strategies for qualitative research. Aldine Transaction.

Lebel, C., MacKinnon, A., Bagshawe, M., Tomfohr-Madsen, L., \& Giesbrecht, G. (2020). Elevated depression and anxiety symptoms among pregnant individuals during the COVID-19 pandemic. Journal of Affective Disorders, 277(July), 5-13. https://doi.org/10.1016/j.jad.2020.07.126

Lima, S. P., Santos, E. K. A., Erdmann, A. L. \& Souza, A. I. J. (2018). Desvelando o significado da experiência vivida para o ser-mulher na amamentação com complicações puerperais. Texto Contexto Enferm, 27(1), e0880016. https://doi.org/10.1590/0104-07072018000880016

Mazzo, M. H.S.N., Brito, R. S., Silva, I. C. G., Feitosa, M. M., Lima, M. S. E., \& Silva, E. C. P. (2018). Percepção das puérperas sobre seu período pós-parto. Investig Enferm., 20(2), 1-9. https://doi.org/10.11144/Javeriana.ie20-2.ppsp.

Mead, G. H. (1970). Mind, self and society: From the standpoint of a social behaviorist. The University of Chicago Press, 179(1).

Mortazavi, F., Mehrabad, M., \& KiaeeTabar, R. (2021). Pregnant women's well-being and worry during the COVID-19 pandemic: a comparative study. BMC Pregnancy and CHildbirth, 4(21), 1-22. https://doi.org/10.1186/s12884-021-03548-4.

Nanjundaswamy, M. H., Shiva, L., Desai, G., Ganjekar, S., Kishore, T., Ram, U., Satyanarayana, V., Thippeswamy, H., \& Chandra, P. S. (2020). COVID-19related anxiety and concerns expressed by pregnant and postpartum women-a survey among obstetricians. Archives of Women's Mental Health, 23(6), 787790. https://doi.org/10.1007/s00737-020-01060-w.

Naurin, E., Markstedt, E., Stolle, D., Enström, D., Wallin, A., Andreasson, I., Attebo, B., Eriksson, O., Martinsson, K., Elden, H., Linden, K., \& Sengpiel, V. (2021). Pregnant under the pressure of a pandemic: a large-scale longitudinal survey before and during the COVID-19outbreak. European Journal of Public Health, 31(1), 7-13. https://doi.org/10.1093/eurpub/ckaa223

Rezende, J. (2015). Obstetrícia Fundamental. (13a ed.), Guanabara Koogan.

Rice, K., \& Williams, S. (2021). Women's postpartum experiences in Canada during the COVID-19 pandemic: a qualitative study. CMAJ Open, 9(2), E556E562. https://www.cmajopen.ca/content/9/2/E556 
Sahin, B. M., \& Kabakci, E. Nur. (2021). The experiences of pregnant women during the COVID-19 pandemic in Turkey: a qualitative study. Women Birth., 34(2), 162-169. https://doi.org/10.1016/j.wombi.2020.09.022.

Sociedade Brasileira de Pediatria. (SBP). (2020). Prevenção e Abordagem da Infecção por COVID-19em mães e Recém-Nascidos, em Hospitais-Maternidades. Departamento Científico de Neonatologia - Sociedade Brasileira de Pediatria. https://www.sbp.com.br/imprensa/detalhe/nid/sbp-divulga-nota-de-alerta-sobreprevencao-e-abordagem-da-infeccao-por-Covid-19-em-maes-e-recem-nascidos/

Silva, A. L. D. (2005). Ensaios em Saúde Coletiva: Entrevista em Profundidade como Técnica de Pesquisa Qualitativa em Saúde Coletiva. Saúde Coletiva, 02(7),71. https://www.redalyc.org/pdf/842/84220794001.pdf

Silva, J. M. S., Cardoso, V. C., Abreu, K. E., \& Silva, L. S. A. (2020 a). A feminização do cuidado e a sobrecarga da mulher-mãe na pandemia. Revista Feminismos, 8(3), 149-161. https://periodicos.ufba.br/index.php/feminismos/article/view/42114/23913

Silva, L. A. T., Fonseca, V. M., Oliveira, M. I. C., Silva, K. S., Ramos, E. G., \& Gama, S. G. N. (2020 b). Professional who attended childbirth and breastfeeding in the first hour of life. Rev Bras Enferm, 73(2), e20180448. https://doi.org/ 10.1590/0034-7167-2018-0448

Silva, M. L. L. dos S., Santos, L. R.., Pereira, B. M. de C.., Veiga, A.V. M.., Mass, D. W., Attem, M. S., \& Santos, L. M. de S. A. dos. (2021). Impacto da pandemia de SARS-CoV-2 na saúde mental de gestantes e puérperas: uma revisão integrativa. Research, Society and Development, 10(10), e484101019186, http://dx.doi.org/10.33448/rsd-v10i10.19186.

Strauss, A., \& Corbin, J. (2008). Pesquisa qualitativa: técnicas e procedimentos para o desenvolvimento de teoria fundamentada. (2a ed.), Artmed.

Trilla, A. (2020). Un mundo, una salud: la epidemia por el nuevo coronavirus COVID-19. Medicina Clínica, 154(5), 175. https://www.elsevier.es/es-revistamedicina-clinica-2-pdf-S002577532030141X

World Health Organization (WHO). (2020). Campaigns. Year of the nurse and midwife 2020. Geneve. https://www.who.int/campaigns/annual-theme/year-ofthe-nurse-and-the-midwife-2020\#: :text=The\%20world\%20needs\%209\%20million,the\%20Nurse $\% 20$ and $\% 20$ the $\% 20 \mathrm{Midwife}$.

World Health Organization (WHO). (2020). Director-General's opening remarks at the media briefing on COVID-19-10 August 2020. Suiça: Genebra https://www.who.int/dg/speeches/detail/who-director-general-s-opening-remarks-at-the-media-briefing-on-Covid-19---10-august-2020. 